\title{
Hazardous Drinking among Students over a Decade of University Policy Change: Controlled Before-and-After Evaluation
}

\author{
Kypros Kypri ${ }^{1,2, *}$, Brett Maclennan ${ }^{1}$, Kimberly Cousins ${ }^{1}$ and Jennie Connor ${ }^{1}$ \\ 1 Department of Preventive and Social Medicine, University of Otago, Dunedin 9016, New Zealand; \\ brett.maclennan@otago.ac.nz (B.M.); kimberly.cousins@ipru.otago.ac.nz (K.C.); \\ jennie.connor@otago.ac.nz (J.C.) \\ 2 School of Medicine and Public Health, University of Newcastle, Newcastle 2308, Australia \\ * Correspondence: kypros.kypri@newcastle.edu.au; Tel.: +61-2-4042-0536
}

Received: 9 August 2018; Accepted: 27 September 2018; Published: 28 September 2018

\begin{abstract}
Background: Responding to high levels of alcohol-related harm among students, a New Zealand university deployed a security and liaison service, strengthened the Student Code of Conduct, increased its input on the operation of alcohol outlets near campus, and banned alcohol advertising on campus. We estimated the change in the prevalence of alcohol consumption patterns among students at the university compared with other universities. Methods: We conducted a controlled before-and-after study with surveys in residential colleges at the target university in 2004 and 2014, and in random samples of students at the target university and three control universities in 2005 and 2013. The primary outcome was the prevalence of recent intoxication, while we analysed drinking per se and drinking in selected locations to investigate mechanisms of change. Results: The 7-day prevalence of intoxication decreased from 45\% in 2004 to 33\% in 2014 (absolute difference: 12\%; $95 \%$ CI: $7 \%$ to $17 \%$ ) among students living in residential colleges, and from $40 \%$ in 2005 to $26 \%$ in 2013 (absolute difference: $14 \%$; $95 \%$ CI: $8 \%$ to $20 \%$ ) in the wider student body of the intervention university. The intervention effect estimate, representing the change at the intervention university adjusted for change at other universities ( $\mathrm{aOR}=1.30 ; 95 \% \mathrm{CI}$ : 0.89 to 1.90 ), was consistent with a benefit of intervention but was not statistically significant $(p=0.17)$. Conclusion: In this period of alcohol policy reform, drinking to intoxication decreased substantially in the targeted student population. Policy reforms and coincidental environmental changes may each have contributed to these reductions.
\end{abstract}

Keywords: college; university; drinking; alcohol; intoxication; policy

\section{Introduction}

University students in Australasia, North America, and Europe have a high prevalence of hazardous drinking [1-4]. Alcohol consumption increases markedly among students upon entering university and throughout first year [5,6], while the increase among peers who do not attend university is less pronounced [6,7]. Studies have found a higher prevalence of hazardous drinking among students compared to their non-student peers [8,9], and university attendance may increase the risk of alcohol problems later in life $[10,11]$.

Many students suffer acute harm from the intoxicating effects of their own and others' drinking [1,2,4,12-17]. Additionally, members of the wider community living close to universities, particularly campuses with a high prevalence of hazardous drinking, are more likely to sustain damage to property, encounter vomit on walkways, witness people urinating, and be exposed to excessive noise, compared to those residing further away [18]. 
The University of Otago is one of eight universities in New Zealand (population 4.7 million). Located in Dunedin (population 120,000), and the majority of Otago students live in residential colleges and shared houses surrounding the campus in North Dunedin [19]. Between 2006 and 2009, in response to growing concern about disorderly behaviour [20-24], the university implemented several initiatives. A 2006 amendment of the Code of Student Conduct [25] enabled the university to reprimand and expel students for disorderly behaviour occurring on and off campus. In 2007, the University established Campus Watch, a security and liaison programme designed to enforce the code and support students and other residents of North Dunedin [26]. In 2009, the University banned alcohol advertising and sponsorship at events held on campus, and at university-organised events off-campus [27].

Residential colleges tightened their alcohol policies in this period [28], and the university began to monitor applications by commercial enterprises to sell alcohol in North Dunedin, objecting to licence renewals for premises that seemed to encourage excessive drinking. In 2009-2010, the University purchased two of the four large pubs next to campus [29,30], converting them into offices and a study centre. Another premises closed in 2013 [31] and re-opened in May 2016 as a 'gastropub' offering high-end beer and food. These pubs had been student institutions in the folklore of the university for decades [32].

The broad view within the university administration is that hazardous drinking and disorderly behaviour have decreased because of these changes [28]. An evaluation of Campus Watch found that drinking decreased between 2005 and 2009 among Otago students compared with students at other New Zealand (NZ) universities [33].

In this study, we examined changes in the prevalence of drinking, recent intoxication, and drinking at various locations among Otago students between 2004/2005 and 2013/2014, encompassing the period in which the aforementioned policies were introduced. This builds on our previous research [33] by including longer pre- and post-policy periods that also capture the implementation of the alcohol advertising ban. In addition, it includes surveys at residential colleges because they house a large proportion of first-year students, a group at particularly high risk of hazardous drinking [5].

\section{Methods}

NZ's Multi-Region Ethics Committee (MEC/05/01/013) and the University of Otago Human Ethics Committee (01/117, 12/278, 14/085) approved the survey protocols.

\subsection{Residential College Alcohol Surveys (RCAS)}

We conducted a web survey of University of Otago students living in 12 Dunedin residential colleges, in April-May 2004, halfway between the beginning of the academic year and first semester exams (see http://ipru3.otago.ac.nz/demo/halls2004/). We employed many of the same questions in a web survey of the same colleges, plus two new colleges, in April-May 2014 (see http:/ /ipru3. otago.ac.nz/demo/halls2014/). The questions relied upon for the comparison reported were worded identically in the pre- and post-study surveys.

The sampling frame was the list of residents held by the university. We sent personalised letters to all residents (2004: $n=2497 ; 2014: n=3262)$ inviting them to participate by clicking on a personalised hyperlink sent to their university e-mail account. We sent up to one reminder letter and three reminder e-mails to residents who had not responded.

\subsection{Tertiary Student Health Surveys (TSHS)}

We conducted web surveys of randomly selected full-time intramural students aged 17-24 years, in April-May of 2005 and 2013 (see http:/ /ipru3.otago.ac.nz/demo/) at participating NZ universities. The data collection procedures are described in detail elsewhere [2,3]. 


\subsection{Measures}

Drinking patterns. We asked RCAS participants about their drinking over the previous seven days, four weeks, and the previous calendar year (the NZ academic year runs from February to November). We classified drinkers as respondents who reported alcohol consumption during any of these periods.

We asked participants who had consumed alcohol in the previous calendar year to complete the Alcohol Use Disorders Identification Test (AUDIT) [34] in relation to that year. As the vast majority of college residents are first-year students, this typically reflected their pre-university drinking. We classified respondents scoring $\geq 8$ on the AUDIT as having a hazardous drinking pattern upon taking up residence in the college. TSHS participants were asked about their alcohol consumption in the previous seven days, four weeks, and 12 months. We classified respondents as drinkers if they had consumed alcohol in any of these periods.

Intoxication and locations of drinking in the previous seven days. We asked respondents who reported drinking in the previous seven days (7-day drinkers) to complete a retrospective 7-day record for each of four location types (pub/bar/nightclub, residential college, private residence, other) in which they had consumed alcohol, indicating the number of standard drinks (10 g ethanol) and the duration of drinking in hours. We used this information to estimate a blood alcohol concentration (EBAC) for each drinking occasion [35] and designated residents with EBAC $>0.08 \mathrm{~g} / \mathrm{dL}$ to have become intoxicated. We assigned EBACs of zero to non-7-day drinkers.

\subsection{Analysis}

We used Stata/SE 13.1 (Stata, College Station, TX, USA) [36], adjusting the TSHS data for the sampling design, by applying weights reflecting the stratified sampling of Māori and non-Māori students. Prevalence fractions of drinking, 7-day intoxication, and drinking at various locations were compared for the 2004 and 2014 RCAS responses, and 2005 and 2013 TSHS responses. We estimated changes in 7-day intoxication prevalence separately for all respondents (i.e., including those who had not consumed alcohol in the previous seven days), and 7-day drinkers. We used logistic regression to weight estimates from the later surveys for changes between survey waves in distributions of participant gender, age, and ethnicity. We adjusted the 2014 RCAS intoxication estimates for past-year hazardous drinking to account for differences in pre-university drinking. We estimated change in the prevalence of intoxication at Otago relative to the other universities using an intervention*survey wave interaction term in a logistic regression model. We inflated standard errors to cluster respondents within universities and residential colleges, and when estimating differences in mean per-occasion consumption between RCAS waves.

\section{Results}

Of the 2497 Otago students living in the Dunedin residential colleges in 2004, 64\% completed the questionnaire. A further 3\% submitted responses meeting the minimum data requirement. These figures for $2014(n=3262)$ were $56 \%$ and $3 \%$ respectively.

Four universities (Otago, Lincoln, Victoria, and Waikato) participated in both the 2005 and the 2013 TSHS. Of the 854 Otago students invited to participate in 2005, 73\% completed the questionnaire or submitted responses meeting the minimum data requirement. The response fraction in $2013(n=1228)$ was $61 \%$. The combined response fractions at the other universities were $66 \%(n=2152)$ in 2005 and $42 \%(n=3301)$ in 2013.

Approximately two-thirds of RCAS and TSHS respondents were women (Table 1). The majority of RCAS respondents were aged 18 years, while over half of the TSHS respondents were aged $\geq 20$ years. 
Table 1. Demographic characteristics of survey samples.

\begin{tabular}{|c|c|c|c|c|c|c|c|c|}
\hline \multicolumn{4}{|c|}{ NZ Universities (TSHS) } & \multicolumn{4}{|c|}{ Dunedin Residential Colleges (RCAS) } & \\
\hline \multicolumn{2}{|c|}{2013} & \multicolumn{2}{|c|}{2005} & \multicolumn{2}{|c|}{2014} & \multicolumn{2}{|c|}{2004} & \\
\hline $\begin{array}{c}\text { Other }^{1} \\
(n=1434) \\
\%\end{array}$ & $\begin{array}{c}\text { Otago } \\
(n=730) \\
\%\end{array}$ & $\begin{array}{c}\text { Other }^{1} \\
(n=1356) \\
\%\end{array}$ & $\begin{array}{c}\text { Otago } \\
(n=617) \\
\%\end{array}$ & $\begin{array}{c}\text { Population } \\
(n=3261) \\
\% \\
\end{array}$ & $\begin{array}{c}\text { Respondents } \\
(n=1941) \\
\%\end{array}$ & $\begin{array}{c}\text { Population } \\
(n=2497) \\
\%\end{array}$ & $\begin{array}{c}\text { Respondents } \\
(n=1662) \\
\%\end{array}$ & \\
\hline $\begin{array}{l}32 \\
68\end{array}$ & $\begin{array}{l}36 \\
64\end{array}$ & $\begin{array}{l}40 \\
60\end{array}$ & $\begin{array}{l}35 \\
65\end{array}$ & $\begin{array}{l}43 \\
57\end{array}$ & $\begin{array}{l}34 \\
66\end{array}$ & $\begin{array}{l}41 \\
59\end{array}$ & $\begin{array}{l}38 \\
62\end{array}$ & $\begin{array}{l}\text { Gender } \\
\text { Male } \\
\text { Female }\end{array}$ \\
\hline $\begin{array}{c}14 \\
70 \\
9 \\
4 \\
4\end{array}$ & $\begin{array}{l}19 \\
69 \\
7 \\
2 \\
3\end{array}$ & $\begin{array}{c}19 \\
61 \\
9 \\
3 \\
8 \\
\end{array}$ & $\begin{array}{c}11 \\
73 \\
6 \\
1 \\
9\end{array}$ & $\begin{array}{c}15 \\
74 \\
6 \\
3 \\
2 \\
\end{array}$ & $\begin{array}{c}13 \\
77 \\
5 \\
3 \\
3\end{array}$ & $\begin{array}{c}16 \\
77 \\
3 \\
1 \\
3\end{array}$ & $\begin{array}{c}16 \\
77 \\
3 \\
1 \\
3\end{array}$ & $\begin{array}{c}\text { Ethnicity } \\
\text { Asian } \\
\text { European } \\
\text { Māori } \\
\text { Pacific Islander } \\
\text { Other }\end{array}$ \\
\hline $\begin{array}{l}- \\
- \\
-\end{array}$ & $\begin{array}{l}- \\
- \\
-\end{array}$ & $\begin{array}{l}- \\
- \\
-\end{array}$ & $\begin{array}{l}- \\
- \\
- \\
-\end{array}$ & $\begin{array}{c}84 \\
11 \\
3 \\
3\end{array}$ & $\begin{array}{c}82 \\
11 \\
4 \\
3\end{array}$ & $\begin{array}{c}78 \\
13 \\
4 \\
5\end{array}$ & $\begin{array}{c}78 \\
13 \\
4 \\
5\end{array}$ & $\begin{array}{c}\text { Year of study } \\
\text { First } \\
\text { Second } \\
\text { Third } \\
\text { 4th year or above }\end{array}$ \\
\hline
\end{tabular}

${ }^{1}$ Lincoln, Victoria and Waikato universities. RCAS: T Residential College Alcohol Surveys; HS: Tertiary Student Health Surveys. 
Smaller proportions of men, those aged $>18$ years, and Asian students responded to the 2014 RCAS compared with 2004 (Table 1), while proportions of Māori, Pacific, and first-year students were larger. At Otago, there was a larger proportion of Asian respondents in the 2013 TSHS than in 2005, and a smaller proportion of European and "Other" ethnicities. At the other three universities combined, there was a smaller proportion of Asian respondents in 2013 than in 2005, and larger proportions of women, 18-19-year-olds, and students of European ethnicities.

\subsection{Drinking Patterns}

The proportion of respondents who were past-year or past-four-week drinkers did not change between 2004 and 2014 (Table 2), but the proportion who drank in the preceding seven days was smaller in 2014 than in 2004.

Table 2. Changes in drinking patterns.

\begin{tabular}{|c|c|c|c|c|c|}
\hline \multirow{3}{*}{ Residential College Alcohol Surveys (RCAS) } & \multicolumn{3}{|c|}{ Year } & \\
\hline & \multirow{2}{*}{$\begin{array}{c}2004 \\
\%\end{array}$} & \multicolumn{2}{|c|}{2014} & & \\
\hline & & $\%$ & $\operatorname{Adj}^{2}{ }^{2}$ & \multicolumn{2}{|c|}{$\begin{array}{l}\text { Change }^{1} \\
95 \% C I\end{array}$} \\
\hline \multicolumn{6}{|l|}{ All respondents } \\
\hline Prevalence of drinking & 93.6 & 95.5 & 95.0 & 1.4 & $(-0.6,3.4)$ \\
\hline \multicolumn{6}{|l|}{ Drinkers only ${ }^{3}$} \\
\hline Past 4 weeks & 92.0 & 90.4 & 91.1 & -0.9 & $(-3.7,2.1)$ \\
\hline Past 7 days & 73.9 & 65.8 & 68.7 & $-5.2 *$ & $(-9.1,-1.2)$ \\
\hline \multirow[t]{3}{*}{ Tertiary Student Health Surveys (TSHS) } & \multicolumn{3}{|c|}{ Year } & \multirow{2}{*}{\multicolumn{2}{|c|}{ Change ${ }^{1}$}} \\
\hline & 2005 & & & & \\
\hline & $\%$ & $\%$ & $\operatorname{Adj}^{2}{ }^{2}$ & $\%$ & $95 \% C I$ \\
\hline \multicolumn{6}{|l|}{$\begin{array}{l}\text { All respondents } \\
\text { Prevalence of drinking }\end{array}$} \\
\hline Otago & 91.7 & 90.1 & 91.0 & -0.7 & $(-4.4,3.0)$ \\
\hline Lincoln, Victoria, Waikato & 87.2 & 86.6 & 83.8 & $-3.4^{*}$ & $(-6.5,-0.2)$ \\
\hline \multicolumn{6}{|l|}{$\begin{array}{l}\text { Drinkers only }{ }^{3} \\
\text { 4-week drinking prevalence }\end{array}$} \\
\hline Otago & 95.0 & 90.9 & 92.0 & -3.0 & $(-6.2,0.2)$ \\
\hline $\begin{array}{l}\text { Lincoln, Victoria, Waikato } \\
\text { 7-day drinking prevalence }\end{array}$ & 91.1 & 88.0 & 86.9 & $-4.2^{* *}$ & $(-7.3,-1.0)$ \\
\hline Otago & 71.2 & 65.3 & 67.2 & -4.1 & $(-10.3,2.2)$ \\
\hline Lincoln, Victoria, Waikato & 59.4 & 62.1 & 61.0 & 1.6 & $(-3.0,6.3)$ \\
\hline
\end{tabular}

Hazardous drinking in the year prior to becoming a resident was also less common in 2014 than in 2004 (difference: $-12.8 \%, 95 \%$ CI: $-17.1 \%$ to $-8.4 \%$ ). Seven-day drinkers consumed less per drinking occasion in 2014 (mean $=7.9$ standard drinks; $79 \mathrm{~g}$ ethanol) than in 2004 (mean = 9.7 standard drinks; $97 \mathrm{~g}$ ethanol), the difference attenuating slightly after adjustment for changes in respondent demographic characteristics between the surveys (difference: $1.4,95 \%$ CI: 0.9 to 2.0 ).

Table 2 also shows changes in drinking status among Otago students versus students at other universities. Past-year drinking decreased at the other universities, but not at Otago. The four-week prevalence of drinking decreased overall, but non-significantly at Otago. Conversely, against a backdrop of no change at the other universities, 7-day drinking at Otago decreased, but not significantly.

\subsection{Recent Intoxication}

Table 3 summarises changes in the 7-day prevalence of intoxication, which decreased among residential college respondents and the subset of 7-day drinkers. A difference remained after adjusting 
for past-year hazardous drinking between the surveys (difference among all respondents: $-7.4 \%$; $95 \%$ CI: $-11.8 \%$ to $-3 \%$; among 7 -day drinkers only: $-7.7 \%$; $95 \%$ CI: $-12.3 \%$ to $-3.2 \%$ ).

Table 3. Changes in the 7-day prevalence of intoxication between surveys.

\begin{tabular}{|c|c|c|c|c|c|c|}
\hline \multirow[t]{3}{*}{ Residential College Alcohol Surveys (RCAS) } & \multicolumn{3}{|c|}{ Year } & \multirow{2}{*}{\multicolumn{3}{|c|}{ Change $^{1}$}} \\
\hline & \multirow{2}{*}{$\begin{array}{c}2004 \\
\%\end{array}$} & \multicolumn{2}{|c|}{2014} & & & \\
\hline & & $\%$ & $\operatorname{Adj}^{2}$ & $\%$ & $95 \% C I$ & $\begin{array}{l}\text { Relative } \\
\text { change }\end{array}$ \\
\hline \multicolumn{7}{|l|}{$\begin{array}{l}\text { Intoxicated }(E B A C>0.08) \text { in the last } 7 \text { days } \\
\text { Residential colleges }\end{array}$} \\
\hline All respondents & 44.9 & 33.4 & 32.7 & $-12.1^{* *}$ & $(-17.1,-7.1)$ & $-27.0 \%$ \\
\hline 7-day drinkers & 67.2 & 54.9 & 54.8 & $-12.4^{* *}$ & $(-17.2,-7.5)$ & $-18.5 \%$ \\
\hline \multirow[t]{3}{*}{ Tertiary Student Health Surveys (TSHS) } & \multicolumn{3}{|c|}{ Year } & & & \\
\hline & 2005 & & 13 & & Change $^{1}$ & \\
\hline & $\%$ & $\%$ & $A d j^{2}$ & $\%$ & $95 \% C I$ & $\begin{array}{l}\text { Relative } \\
\text { change }\end{array}$ \\
\hline \multicolumn{7}{|l|}{ Intoxicated $(E B A C>0.08)$ in the last 7 days } \\
\hline All respondents & 40.3 & 24.9 & 26.1 & $-14.2^{* *}$ & $(-20.3,-8.1)$ & $-35.2 \%$ \\
\hline 7-day drinkers & 60.1 & 41.8 & 42.6 & $-17.4^{* *}$ & $(-25.6,-9.2)$ & $-29.0 \%$ \\
\hline \multicolumn{7}{|l|}{ Lincoln, Victoria, and Waikato universities } \\
\hline All respondents & 24.5 & 19.1 & 18.2 & $-6.4^{* *}$ & $(-9.9,-2.8)$ & $-26.1 \%$ \\
\hline 7-day drinkers & 45.9 & 34.8 & 35.1 & $-10.8^{* *}$ & $(-16.8,-4.9)$ & $-23.5 \%$ \\
\hline
\end{tabular}

The 7-day prevalence of intoxication decreased between 2005 and 2013 at Otago and at the other universities combined (Table 3), and the absolute change at Otago was larger than at other universities overall and among 7-day drinkers. The difference between the change at Otago relative to the other universities among all respondents was significant (ratio of ORs: $1.46,95 \%$ CI: 1.02 to $2.09, p=0.04$ ) but not after adjustment for changes in respondent demographic characteristics between the surveys (ratio of ORs: $1.30,95 \%$ CI: 0.89 to 1.90, $p=0.17$ ). Unadjusted (ratio of ORs: $1.34,95 \%$ CI: 0.87 to 2.04, $p=0.18$ ) and adjusted (ratio of ORs: 1.28, 95\% CI: 0.82 to 1.99, $p=0.27$ ) estimates among 7-day drinkers only were both non-significant.

\subsection{Drinking Locations in the Past 7 Days}

The proportion of 7-day drinkers who had consumed alcohol at on-license premises in the preceding week fell substantially from 2004 to 2014 (Table 4). The prevalence of drinking in residential colleges and 'other' locations remained the same, while the proportion consuming alcohol at private residences was higher in 2014 than in 2004.

There were significant decreases between 2005 and 2013 in the proportion of 7-day drinkers at Otago who had consumed alcohol at private residences and on-license premises in the previous week (Table 4). There was no change in the proportion who had consumed alcohol at a residential college, and there was a non-significant increase in the proportion who had consumed alcohol at 'other' locations.

A decrease between surveys in the proportion of 7-day drinkers at the other universities who consumed alcohol at private residences and on-license premises in the previous week was significant (Table 4). There was no change in the prevalence of students drinking in residential colleges and 'other' locations. 
Table 4. Prevalence of drinking at residential colleges, private residences, on-licence premises and 'other' locations among students who drank alcohol in the preceding seven days.

\begin{tabular}{|c|c|c|c|c|c|}
\hline \multirow{3}{*}{ Residential College Alcohol Surveys (RCAS) } & \multicolumn{3}{|c|}{ Year } & \multirow{2}{*}{\multicolumn{2}{|c|}{ Change $^{1}$}} \\
\hline & \multirow{2}{*}{$\begin{array}{c}2004 \\
\%\end{array}$} & \multicolumn{2}{|c|}{2014} & & \\
\hline & & $\%$ & $A d j \%{ }^{2}$ & $\%$ & $95 \% \mathrm{CI}$ \\
\hline \multicolumn{6}{|l|}{ Drinking locations in the last 7 days } \\
\hline \multicolumn{6}{|l|}{ University of Otago college residents } \\
\hline Residential college & 78.9 & 77.5 & 77.3 & -1.2 & $(-7.4,4.3)$ \\
\hline Private residence & 26.5 & 32.5 & 33.7 & $7.2^{*}$ & $(0.7,13.7)$ \\
\hline Pub & 82.0 & 57.7 & 58.4 & $-23.6^{* *}$ & $(-28.8,-18.4)$ \\
\hline Other ${ }^{3}$ & 20.8 & 22.8 & 23.8 & 3.1 & $(-0.6,6.7)$ \\
\hline \multirow[t]{3}{*}{ Tertiary Student Health Surveys (TSHS) } & \multicolumn{3}{|c|}{ Year } & \multirow{2}{*}{\multicolumn{2}{|c|}{ Change 1}} \\
\hline & \multirow{2}{*}{$\begin{array}{c}2005 \\
\%\end{array}$} & \multicolumn{2}{|c|}{2013} & & \\
\hline & & $\%$ & $\operatorname{Adj}^{2}{ }^{2}$ & $\%$ & $95 \% C I$ \\
\hline \multicolumn{6}{|l|}{ Drinking locations in the last 7 days } \\
\hline \multicolumn{6}{|l|}{ Otago students } \\
\hline Residential college & 16.8 & 15.9 & 19.4 & 2.6 & $(-2.7$ to 7.9$)$ \\
\hline Private residence & 77.1 & 70.4 & 67.8 & $-9.2 * *$ & $(-16.1$ to -2.4$)$ \\
\hline Pub & 73.7 & 51.9 & 53.2 & $-20.5^{* *}$ & $(-28.4$ to -12.6$)$ \\
\hline Other ${ }^{3}$ & 24.2 & 31.4 & 30.4 & 6.2 & $(-1.3$ to 13.7$)$ \\
\hline \multicolumn{6}{|l|}{ Lincoln, Victoria, Waikato students } \\
\hline Residential College & 12.1 & 15.9 & 14.4 & 2.3 & $(-1.3$ to 6.0$)$ \\
\hline Private residence & 77.3 & 67.6 & 67.9 & $-9.4^{* *}$ & $(-14.8$ to -4.1$)$ \\
\hline Pub & 61.5 & 50.9 & 49.9 & $-11.6^{* *}$ & $(-17.7,-5.4)$ \\
\hline Other $^{3}$ & 25.8 & 26.3 & 26.7 & 0.9 & $(-4.6$ to 6.5$)$ \\
\hline
\end{tabular}

\subsection{Sensitivity Analysis on Residential College Alcohol Survey Data}

To investigate bias from selective non-responses, we adopted an approach previously employed to investigate non-response bias in survey data [37]. We estimated the proportion of 2004 respondents who reported drinking to intoxication among those who had participated by day 18 (i.e., the day we reached a response fraction of $59 \%$, our final response fraction in 2014). The difference between 7-day intoxication prevalence (all respondents and 7-day drinkers only) among all respondents in 2004, versus those who responded by day 18 , was $<1 \%$.

We then estimated differences in the proportion of respondents drinking to intoxication in 2004 versus 2014, based on the assumption that the true 7-day prevalence of intoxication among non-respondents was $20 \%, 33 \%, 50 \%$, or $100 \%$ higher than among respondents. The result was differences in estimates from 2004 to 2014 by up to $1.5 \%$.

\section{Discussion}

Our findings suggest that while the proportion of drinkers in the Otago student population did not change in the decade between the surveys, a smaller proportion of drinkers consumed alcohol or became intoxicated in the preceding 7 days. This was true even after adjusting for differences in the pre-university drinking profiles of the populations between surveys. Intoxication was also less prevalent over time among university students overall in NZ. The reduction (of around a third) was large among Otago students, but not significantly larger than it was among students at other universities. Dunedin college residents drank less per occasion in 2014 than in 2004, mainly driven by substantially decreased drinking in pubs and bars, which was only slightly offset by drinking more in their residential colleges.

In 2014, a smaller proportion of residential college students had consumed alcohol hazardously in the previous calendar year (i.e., before most became residents). This may reflect the greater proportion 
of 16-17-year-olds in residential colleges in 2014. While NZ law does not prohibit the consumption of alcohol at any age, people under 18 years of age cannot purchase it legally, a restriction that research suggests is effective in reducing alcohol-related harm [38]. Accordingly, this change in the demographic composition of the student population may account for some of the differences observed.

The strengths of the study include the equivalent timing of the surveys within the academic calendar, and the use of identical questions and survey methods, facilitating valid comparisons over time and between residents and wider student populations. The sensitivity analyses on RCAS-based estimates suggested that the differences in response fractions are unlikely to have substantially biased estimates of change.

The sampling design used in the TSHS meant a similar sensitivity analysis on these estimates was infeasible. Previous studies suggest the prevalence of drinking is underestimated to a greater extent when response rates are lower [37,39]. Accordingly, over-estimation of differences in intoxication prevalence between 2005 and 2013 would be less pronounced for Otago given the lesser decline in response rates there ( $12 \%$ versus $24 \%$ at the other universities combined), making this a conservative test of whether the interventions were associated with reduced drinking.

This and other factors may have contributed to our non-significant finding when comparing change in the prevalence of 7-day intoxication at Otago with change at the other universities. In addition to limitations of statistical power, our measure of 7-day intoxication may not have been sensitive enough to detect a modest change in drinking behaviour, for example, going from having 10 drinks in an evening to having two or three fewer drinks, or to spreading the consumption over a longer period, but without reducing their mean estimated BAC to below our threshold for classifying them as intoxicated.

We did not attempt to formally determine whether institutional policies or programmes were introduced at the other universities that could impact on student drinking. Such developments, if effective, would have biased our findings towards the null, potentially masking any effects of the Otago interventions.

While the TSHS allowed for directly comparable control sites (i.e., other universities), the RCAS included residential colleges at Otago only, limiting inferences about the Otago interventions on alcohol consumption in the colleges. It should be noted, however, that the decrease in drinking to intoxication among residents is consistent with the direction of change in the wider Otago student population, albeit of lesser magnitude. The large proportion of first year students living in the residential colleges may have different perceptions and expectations about alcohol use in the university environment than students in the wider population, many of whom are more senior. Those in their first year may be more motivated to drink to intoxication and this could be reinforced by the social aspect of college living.

During the study period, local government alcohol policies focused on the Central Business District rather than North Dunedin [40]. Legislation governing the sale of alcohol changed in 2012, but provisions with the potential to affect student drinking (e.g., Local Alcohol Policies) came into effect after the 2014 survey [41]. An exception is the blood alcohol limit for drivers under 20 years of age being reduced from $0.03 \mathrm{~g} / \mathrm{dL}$ to zero, in 2011. The majority of student accommodation in Dunedin is within walking distance of campus and alcohol outlets [42], and residents do not rely heavily on private cars. Student populations at other universities, where more students rely on private cars, may have moderated their drinking to a greater extent in response to this restriction than those at Otago, potentially biasing estimates toward the null.

It is unlikely that the relative reduction in 7-day drinking and intoxication among Otago students, including those living in residential colleges, merely reflects a national trend or local government interventions. Without a randomised design, we cannot safely infer that they are due, even in part, to the strategies implemented by the university. The marked decrease in drinking at on-license premises makes the pub closures in North Dunedin a strong candidate explanation for the estimated reductions, given that drinking episodes in pubs are more likely to result in intoxication, particularly among men, than drinking in other locations [43]. 
Pub closures, perhaps combined with the blood alcohol limit reduction for driving, may have influenced the number of drinks Otago students consumed per occasion and where they drank. NZ research shows that the proximity of on-licensed premises to university students' homes is associated with their drinking and related problems [44]. The reduction in the number of on-license premises in North Dunedin may have reduced market pressure for cheap drink promotions such that drinking in pubs became less appealing because of high drink prices and reduced physical accessibility requiring longer walks or taxis.

Only a small proportion of Otago students appear to have substituted drinking in pubs with drinking at other locations. There was, however, an increase in the proportion of college residents drinking in private homes in the preceding 7 days. How much these 2014 students drank at private homes compared to what their 2004 predecessors were drinking in pubs is unknown. We found that the amount consumed per occasion by residents was lower in 2014, although the overall amount consumed within residential colleges increased slightly. Focus group research conducted in this population in the early 2000s suggests that residents were drinking at their college before going to a pub [5]. Residents may now be drinking more in their college because drinking in pubs has become comparatively more expensive, and, for most, there are no practical alternative locations to continue drinking. Campus Watch may be reinforcing this by deterring students from drinking in public places around the campus.

Overall, there has been a shift among Otago students to drinking less than weekly and across fewer types of locations, with a large shift away from drinking in pubs. This coincided with a large reduction in the prevalence of intoxication among Otago students, consistent with what we know from previous research. Drinking in pubs, residential colleges, and private residences facilitates heavy drinking and intoxication among NZ university students relative to 'other' locations [43,45]. As found in that focus group research, drinking in pubs after 'pre-loading' at a residential college or private residence probably facilitates heavier drinking episodes.

\section{Conclusions}

The confluence of findings from surveys conducted over a decade, involving students at four NZ universities, and 12 residential colleges in North Dunedin, suggests that with concerted effort, it is possible to change a drinking culture. The university's involvement in objecting to license renewals may have created a tipping point for businesses that had survived by breaching server laws. By issuing a clear statement of institutional values (through the Code of Student Conduct), introducing a policy with highly visible symbolic value (the advertising ban) and implementing a well-resourced prevention programme (Campus Watch), the university began attracting fewer hazardous drinkers. It seems likely that the actions of the university along with the reduction in pubs surrounding campus has helped to reduce hazardous drinking in the Otago student population.

Author Contributions: K.K. conceived of the comparison made in this paper and designed a study with B.M. and J.C. K.K. obtained funding for this comparison. K.C. collected TSHP data under the supervision of K.K. and J.C. B.M. collected RCAS data under the supervision of K.K. in 2004 and independently in 2014. B.M. did the statistical analysis. K.K. and B.M. led the writing of the paper, with input from K.C. and J.C. All of the authors approved the final version of the paper.

Funding: The Tertiary Student Health Surveys were funded by the Health Research Council of New Zealand, the Alcohol Advisory Council of New Zealand, and New Zealand Ministry of Health. The 2004 Residential College Alcohol Survey was funded with a PhD scholarship from the Accident Compensation Corporation of New Zealand, while the 2014 survey was funded by the University of Otago. Professor Kypri's involvement in the research was funded with a fellowship from the National Health and Medical Research Council of Australia. The funders had no involvement in the design, implementation, reporting, or any other aspect of the research. The researchers were free to conduct and write about the research without constraint.

Acknowledgments: We are grateful to the universities, halls of residents, and students who participated in the research.

Conflicts of Interest: The authors declare no conflict of interest 


\section{References}

1. Karam, E.; Kypri, K.; Salamoun, M. Alcohol use among college students: An international perspective. Curr. Opin. Psychiatry 2007, 20, 213-221. [CrossRef] [PubMed]

2. Kypri, K.; Paschall, M.J.; Langley, J.; Baxter, J.; Cashell-Smith, M.; Bourdeau, B. Drinking and Alcohol-Related Harm among New Zealand University Students: Findings from a National Web-Based Survey. Alcohol. Clin. Exp. Res. 2009, 33, 307-314. [CrossRef] [PubMed]

3. Connor, J.; Cousins, K.; Samaranayaka, A.; Kypri, K. Situational and contextual factors that increase the risk of harm when students drink: Case-control and case-crossover investigation. Drug Alcohol Rev. 2014, 33, 401-411. [CrossRef] [PubMed]

4. Hallett, J.; Howat, P.M.; Maycock, B.R.; McManus, A.; Kypri, K.; Dhaliwal, S.S. Undergraduate student drinking and related harms at an Australian university: Web-based survey of a large random sample. BMC Public Health 2012, 12, 37. [CrossRef] [PubMed]

5. Kypri, K.; Langley, J.D.; McGee, R.; Saunders, J.B.; Williams, S. High prevalence, persistent hazardous drinking among New Zealand tertiary students. Alcohol Alcohol. 2002, 37, 457-464. [CrossRef] [PubMed]

6. O'Malley, P.M.; Johnston, L.D. Epidemiology of alcohol and other drug use among American college students. J. Stud. Alcohol Suppl. 2002, 14, 23-39. [CrossRef]

7. Paschall, M.J.; Bersamin, M.; Flewelling, R.L. Racial/Ethnic differences in the association between college attendance and heavy alcohol use: A national study. J. Stud. Alcohol 2005, 66, 266-274. [CrossRef] [PubMed]

8. Kypri, K.; Cronin, M.; Wright, C.S.; Kypri, K.; Cronin, M.; Wright, C.S. Do university students drink more hazardously than their non-student peers? Addiction 2005, 100, 713-714. [CrossRef] [PubMed]

9. Dawson, D.A.; Grant, B.F.; Stinson, F.S.; Chou, P.S. Another look at heavy episodic drinking and alcohol use disorders among college and noncollege youth. J. Stud. Alcohol 2004, 65, 477-488. [CrossRef] [PubMed]

10. Casswell, S.; Pledger, M.; Pratap, S. Trajectories of drinking from 18 to 26 years: Identification and prediction. Addiction 2002, 97, 1427-1437. [CrossRef] [PubMed]

11. Donovan, J.E.; Jessor, R.; Jessor, L. Problem drinking in adolescence and young adulthood. A follow-up study. J. Stud. Alcohol 1983, 44, 109-137. [CrossRef] [PubMed]

12. Perkins, H.W. Surveying the damage: A review of research on consequences of alcohol misuse in college populations. J. Stud. Alcohol Suppl. 2002, 14, 91-100. [CrossRef]

13. Wechsler, H.; Moeykens, B.; Davenport, A.; Castillo, S.; Hansen, J. The adverse impact of heavy episodic drinkers on other college students. J. Stud. Alcohol 1995, 56, 628-634. [CrossRef] [PubMed]

14. Hallett, J.; Howat, P.; McManus, A.; Meng, R.; Maycock, B.; Kypri, K. Academic and personal problems among Australian university students who drink at hazardous levels: Web-based survey. Health Promot. J. Aust. 2013, 24, 170-177. [CrossRef] [PubMed]

15. Hingson, R.W.; Zha, W.; Weitzman, E.R. Magnitude of and Trends in Alcohol-Related Mortality and Morbidity among U.S. College Students Ages 18-24, 1998-2005. J. Stud. Alcohol Drugs Suppl. 2009, 16, 12-20. [CrossRef]

16. McGee, R.; Kypri, K. Alcohol-related problems experienced by university students in New Zealand. Aust. N. Z. J. Public Health 2004, 28, 321-323. [CrossRef] [PubMed]

17. Langley, J.; Kypri, K.; Stephenson, S.C. Secondhand effects of alcohol use among university students: Computerised survey. BMJ 2003, 327, 1023-1024. [CrossRef] [PubMed]

18. Wechsler, H.; Lee, J.E.; Hall, J.; Wagenaar, A.C.; Lee, H. Secondhand effects of student alcohol use reported by neighbors of colleges: The role of alcohol outlets. Soc. Sci. Med. 2002, 55, 425-435. [CrossRef]

19. Cousins, K.; Connor, J.L.; Kypri, K. Reducing alcohol-related harm and social disorder in a university community: A framework for evaluation. Inj. Prev. 2010, 16, e1. [CrossRef] [PubMed]

20. Porteous, D. Student Antics ‘Intolerable'. Otago Daily Times, 4 March 2006.

21. Hepburn, S. Fire Service Hot under Collars about Students. Otago Daily Times, 21 August 2006.

22. Porteous, D. Mayor Wants Convictions. Otago Daily Times, 27 August 2007.

23. Fox, R.; Scott, M. Firefighters Dodge Bottles again on Fiery Night. Otago Daily Times, 16 April 2005.

24. Loughrey, D. Disappointment All Round at Disorderly Castle St Events. Available online: http://www. odt.co.nz/news/dunedin/19316/disappointment-all-round-disorderly-castle-st-events (accessed on 29 January 2016). 
25. University of Otago. Code of Student Conduct. Available online: http://www.otago.ac.nz/proctor/ otago085274.pdf (accessed on 29 January 2016).

26. University of Otago. Campus Watch. Available online: http://www.otago.ac.nz/proctor/campuswatch/ (accessed on 29 January 2016).

27. Rudd, A. University Bans Alcohol Promotion. Available online: http://www.odt.co.nz/on-campus/ university-otago/77988/university-bans-alcohol-promotion (accessed on 29 January 2016).

28. Manins, R. Altering Drinking Culture. Available online: http://www.odt.co.nz/campus/university-otago/ 290081/altering-drinking-culture (accessed on 29 January 2016).

29. Harvey, S. University Buys the 'Bowler'. Available online: http://www.odt.co.nz/on-campus/universityotago/46951/university-buys-039bowler039 (accessed on 29 January 2016).

30. Rudd, A. Varsity Buying, Closing Bar. Available online: http://www.odt.co.nz/on-campus/universityotago/99988/varsity-buying-closing-bar (accessed on 29 January 2016).

31. Elder, V. Captain Cook May Reopen. Available online: http://www.odt.co.nz/news/dunedin/271135/ captain-cook-may-reopen (accessed on 29 January 2016).

32. Russell, M. Scarfies and Alcohol: The Geography of Student Pubs and Drinking in Dunedin; University of Otago: Dunedin, New Zealand, 1999.

33. Cousins, K.; Connor, J.L.; Kypri, K. Effects of the Campus Watch intervention on alcohol consumption and related harm in a university population. Drug Alcohol Depend. 2014, 143, 120-126. [CrossRef] [PubMed]

34. Babor, T.F.; Higgins-Biddle, J.C.; Saunders, J.B.; Monteiro, M.G. AUDIT: The Alcohol Use Disorders Identification Test-Guidelines for Use in Primary Care; World Health Organization: Geneva, Switzerland, 2001.

35. Kypri, K.; Langley, J.; Stephenson, S. Episode-centred analysis of drinking to intoxication in university students. Alcohol Alcohol. 2005, 40, 447-452. [CrossRef] [PubMed]

36. STATA Statistical Software, version 13.1; STATA: College Station, TX, USA, 1985-2013.

37. Kypri, K.; Samaranayaka, A.; Connor, J.; Langley, J.; Maclennan, B. Non-response bias in a web-based health behaviour survey of New Zealand tertiary students. Prev. Med. 2011, 53, 274-277. [CrossRef] [PubMed]

38. Kypri, K.; Davie, G.; McElduff, P.; Connor, J.; Langley, J. Effects of Lowering the Minimum Alcohol Purchasing Age on Weekend Assaults Resulting in Hospitalization in New Zealand. Am. J. Public Health 2014, 104, 1396-1401. [CrossRef] [PubMed]

39. Kypri, K.; Stephenson, S.; Langley, J. Assessment of Nonresponse Bias in an Internet Survey of Alcohol Use. Alcohol Clin. Exp. Res. 2004, 28, 630-634. [CrossRef] [PubMed]

40. Maclennan, B.A. Local Government Alcohol Policy: Community Sentiment and the Policy Development Process. Ph.D. Thesis, University of Otago, Dunedin, New Zealand, 2010.

41. Maclennan, B.; Kypri, K.; Connor, J.; Potiki, T.; Room, R. New Zealand's new alcohol laws: Protocol for a mixed-methods evaluation. BMC Public Health 2016, 16, 29. [CrossRef] [PubMed]

42. Richardson, D. Creating Cultural Change-Campus Watch: A Most Fortunate Experiment. Available online: http:/ / www.slideshare.net/informaoz/david-richardson-paper-for-slideshare-campus-watch-amost-fortunate-experiment (accessed on 28 September 2018).

43. Kypri, K.; Paschall, M.J.; Maclennan, B.; Langley, J.D. Intoxication by drinking location: A web-based diary study in a New Zealand university community. Addict. Behav. 2007, 32, 2586-2596. [CrossRef] [PubMed]

44. Kypri, K.; Bell, M.L.; Hay, G.C.; Baxter, J. Alcohol outlet density and university student drinking: A national study. Addiction 2008, 103, 1131-1138. [CrossRef] [PubMed]

45. Kypri, K.; Paschall, M.J.; Langley, J.D.; Baxter, J.; Bourdeau, B. The role of drinking locations in university student drinking: Findings from a national web-based survey. Drug Alcohol Depend. 2010, 111, $38-43$. [CrossRef] [PubMed]

(C) 2018 by the authors. Licensee MDPI, Basel, Switzerland. This article is an open access article distributed under the terms and conditions of the Creative Commons Attribution (CC BY) license (http:/ / creativecommons.org/licenses/by/4.0/). 